\title{
PULSE TRANSIT TIME - RELIABLE MARKER FOR SLEEP DISTURBANCES AMONG ATHLETES
}

\author{
Krassimir Rankov
}

National Sports Academy „Vassil Levski”, Sofia, Bulgaria

\begin{abstract}
Sleep is essential for everyone and is important for the normal human functioning. Lack of sleep, called sleep deprivation, is a condition leading to poor sports training and achievements. Different factors contribute to sleep deprivation among athletes. Respiratory sleep disorders such as Upper airway resistance syndrome (UARS) and Obstructive Sleep Apnea (OSA) are factors that rebound most to sleep deprivation for certain groups of athletes such as wrestlers, judokas and sumo wrestlers.

The present study investigates the UARS and OSA occurrence in the above mentioned groups of athletes using Pulse Transit Time (PTT) as an early noninvasive indicator of respiratory effort and sympathetic nervous system activity.

Sixty-seven elite athletes, practicing wrestling, sumo wrestling and judo were screened by enquiry for sleep breathing disturbances. The study involved the most suspicious ten cases for sleep-disordered breathing symptoms. They underwent full standard polysomnographic (PSG) examination using Alice 5 System Philips - Respironics Inc. with the registration of PTT.

Among all athletes, regardless of the presence of changes in hemoglobin saturation or apnea-hypopnea index changes (AHI), a significant drop in the PTT value with more than 8-15 ms for sleep stages N1 and N2 ( $<<0.005)$ was observed, as well as with more than 6-8 ms for sleep stage N3 ( $p<0.005)$. We found bigger dependence of PTT by Arousal Index (ArI) than AHI and Desaturation Index (DI). Therefore, PTT can be used as a good indicator of sleep fragmentation before the development of the clinical picture of UARS and OSA.

As a good indicator for inspiratory effort and sympathetic changes in UARS and OSA, PTT gives an opportunity for early diagnosis of respiratory sleep disorders among athletes. Prevention, timely detection and appropriate treatment of sleep disorders before the development of their full clinical picture will improve the processes of recovery and performance in sports practice.
\end{abstract}

Key words: Sleep, Athletes, Pulse Transit Time

\section{INTRODUCTION}

Lack of sleep, called sleep deprivation, is a high stress factor for an individual. It leads to cognitive deficits, deterioration of memory capacity, lowered immunity, heart problems, muscle tremors, increased reaction time etc. This affects one's performance and alertness. In regard to sport, sleep is probably the most important form of recovery and its absence has many negative effects on athletes' perfor- mance and achievements.

Acute sleep deprivation leads to the obvious harmful physiological effects and altered mental status of athletes (VanHelder, Radomski, 1989). Various tests with loads, performed after sleep deprivation, showed decrease of fatigue onset time (Myles et al., 1985; Martin, 1981), change in morning levels of different hormones important for athletes (Remes et al., 1985) and abnormal metabolism, which hampers the delivery 
and storage of energy substrates to muscles so important for endurance (Soussi et al., 2003).

The assessment of sleep deprivation is both subjective and objective. Our goal is always to objectify the problem. In recent years, the newest technique for sleep investigation has become advanced owing to the introduction of more accurate methods and criteria for the objective study of sleep deficit.

The concept of arousals has a long history that is closely related to the development of the neurophysiology of sleep and wakefulness. There are different definitions and different views on the criteria of their scoring (Schieber et al., 1971; Halász et al., 1979; Terzano et al., 1985; Atlas Task Force, 1992; Lofaso et al., 1998 etc.). Arousals during sleep are closely related to the pathophysiology of sleep disorders. The term "arousal" means a temporary condition of awakening during sleep (Atlas Task Force, 1992). According to American Association of Sleep Medicine (AASM) (1992) cortical arousals are pathological phenomena, violating the proper functioning of sleep cycles and fragmenting their structure. They are also defined as short (3-15 seconds) transient signs of wakefulness during sleep, which in most cases is unconscious and does not lead to behavioral awakening. Arousal stimuli may be of a different nature, but the result is always a sleep fragmentation, which leads to poor quality in sleep with normal or even increased duration.

Chronologically autonomic arousal precedes the cortical one (Catcheside al., 2002; Krieger et al., 2003). It is expressed in awakening of the "subcortical" level, including the autonomic nervous system. We can judge about autonomic arousal especially on the increased sympathetic activation in late apneic episodes. An important indicator of this is the time in which the pulse wave travels from the aortic valve to the periphery (plethysmographic sensor of the finger). This is a relatively new in- dicator - pulse transit time (PTT) (Naschitz, 2004). The speed with which this wave travels is proportional to the rigidity of the arterial wall. An acute rise in sympathetic activity which follows an airflow cessation constricts blood vessels, hence, the arterial wall becomes stiffer causing the PTT to shorten. This also interrupts sleep and the result is an increased daytime sleepiness. Moreover, it appears that autonomic arousal can be used as an early indicator of respiratory disorders and cardiovascular risk among patients with mild forms of the Obstructive Sleep Apnea (OSA), particularly those with Upper Airway Resistance Syndrome (UARS) (Pitson, Stradling et al., 1998).

Recurrent episodes of narrowing or complete obstruction of upper airways that characterize OSA cause effects of acute stressors such as hypoxemia, negative intrathoracic pressure, micro-arousals, reoxygenation etc. (Caples et al., 2007).

There is evidence that people with OSA have chronic impaired regulation of cardiovascular homeostasis, as confirmed by disturbed sympathetic regulation and heart rate variability among OSA patients during the day (Somers et al., 1995, Narkiewich et al., 1998). Higher sympathetic activity during autonomous micro-arousal is the earliest indicator of the development of hypertension and increased cardiovascular risk. Detecting autonomic arousals by means of PTT allows a very elegant, patient friendly and cheap way to assess sleep fragmentation without the need of expensive and time-consuming electroencephalogram (EEG) registration (Pitson D. et al., 1994).

\section{AIM OF THE STUDY}

The study was designed to investigate the prevalence of UARS and mild OSA among athletes from certain sports with the use of PTT and to assess consequences for sports performance and recovery. The goal of the 
present study was to establish whether PTT can be used as an early indicator of sleep breathing disturbances among young athletes.

\section{METHODS}

\section{Subjects}

High-performance athletes (wrestlers, sumo wrestlers and judokas) aged $25 \pm 5$ years from the National Sports Academy „Vassil Levski”, Sofia, Bulgaria were recruited for participation in the study. Both an informed consent and an institutional local research ethical approval were obtained for the present study.

\section{Protocol}

All subjects (67 elite athletes - 27 wrestlers $-23 \pm 3$ years; 15 sumo wrestlers -23 \pm 6 years; 10 judokas $-18 \pm 4$ years) were screened by enquiry for sleep-disordered breathing (daytime sleepiness, disturbed sleep, daytime fatigue and loud snoring). An electronic screening device - portable pulse oximetry instrument (OXY-100) was applied after the inquiry. The most suspicious cases $(n=10)$ for sleep breathing disturbances underwent full standard overnight polysomnography (PSG) by means of Alice 5 Philips -Respironics Inc. equipment.

\section{Equipment and measurements}

The polysomnographic recordings consisted of EEG, electrooculogram, electromyogram, electrocardiogram (ECG), chest wall movement, nasal and oral air flow and oxygen saturation. The following parameters were estimated:

PTT - the distance from the top of the Rwave of the ECG to half of the peak of the pulse wave (Plethysmogram) (Figure 1). Normal velocity of PTT is $250-280 \mathrm{~ms}$;

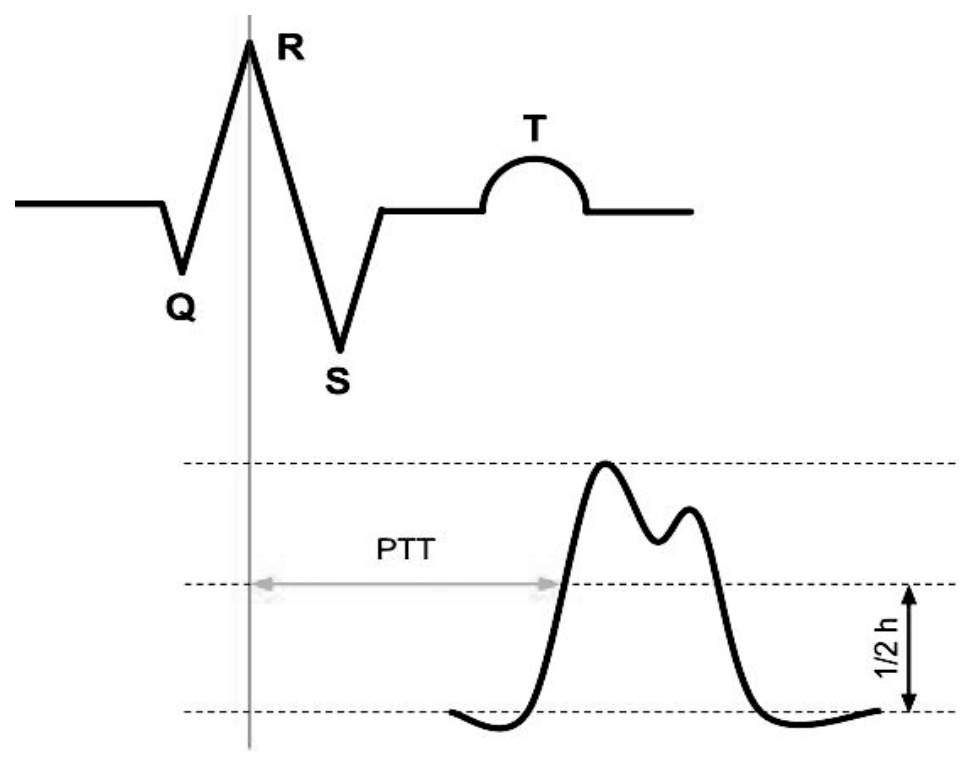

Figure 1. Measurement of PTT.

- Apnea/hypopnea index (AHI) - number of apneas (cessation of both nasal and oral airflow for a minimum of 10 seconds), and hypopneas (a reduction in airflow to $50 \%$ of baseline in association with oxygen desaturation) per hour of sleep;

- Desaturation index (DI) - number of decrement in oxygen saturation below $4 \%$ for a minimum of $10 \mathrm{sec}$ per hour of sleep;

- Arousal index (ArI) - number of desynchronizations in EEG for at least $3 \mathrm{sec}$ after $10 \mathrm{sec}$ period from beginning of given sleep stage.

Indexes AHI, DI and ArI $\leq 5$ are considered normal.

A native PSG record of one of the athletes is shown in Figure 2. 


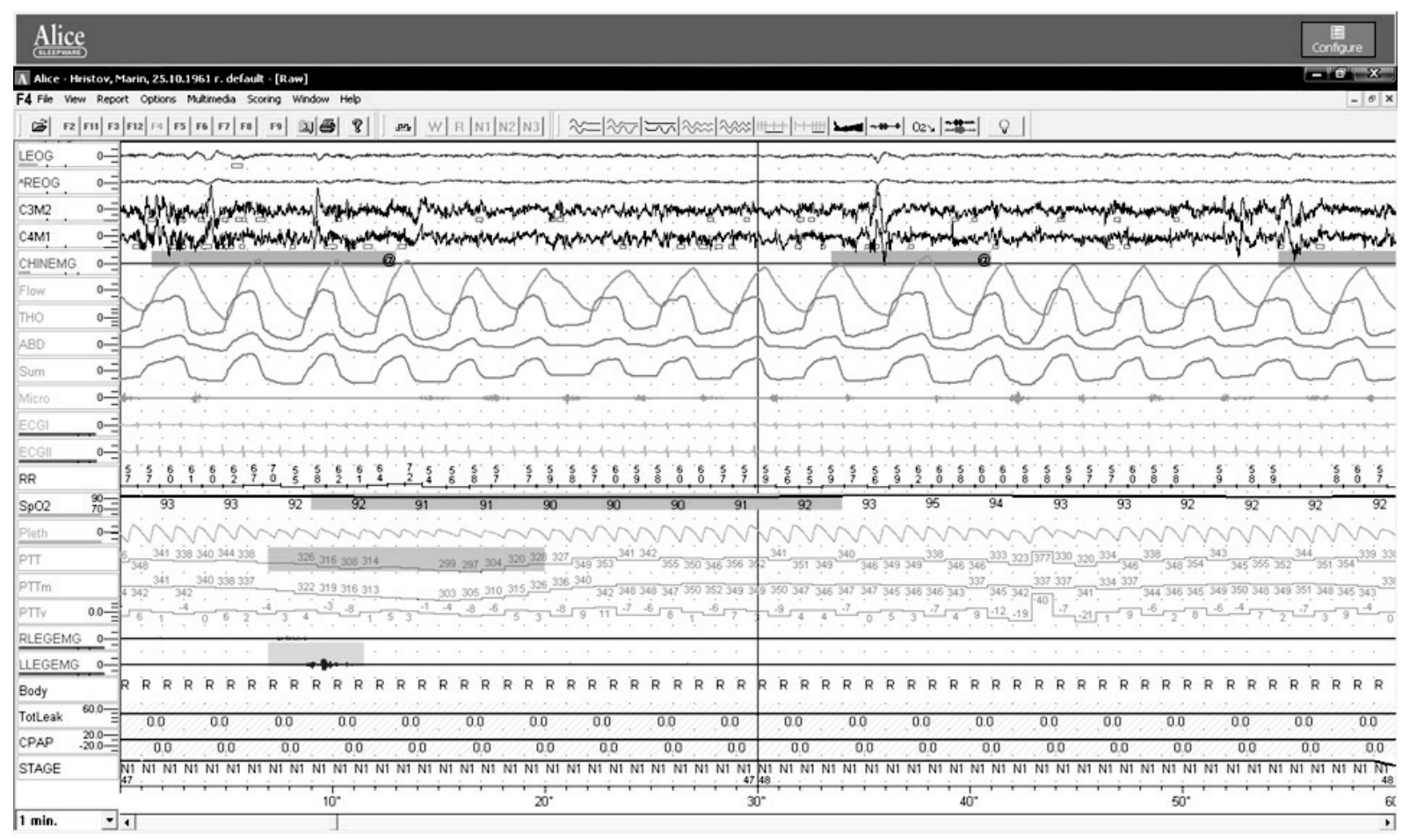

Figure 2. Row PSG data. The highlighted cortical arousals (orange), the desaturation (aqua blue) and PTT shortening (gray) are clearly visible.

\section{RESULTS}

During sleep a normal fluctuation in the value of PTT is observed. The following levels of PTT, according to the relevant stages of sleep, are considered as normal: PTT shortening with up to $15 \mathrm{~ms}$ for sleep stages N1 and N2 and with up to $8 \mathrm{~ms}$ for stage N3.

Figure 3 shows the PTT drop compared to norm. We found significant PTT shortening with more than $15 \mathrm{~ms}$ for sleep stages $\mathrm{N} 1$ and N2 and with more than $8 \mathrm{~ms}$ for stage N3 (Figure 3$)$. In all of the investigated athletes $(n=10)$ PTT shortening was observed, regardless of the presence of change in AHI or desaturation changes. This proves the occurrence of respiratory sleep disturbance in early stage.

\section{PTT drop to norm}

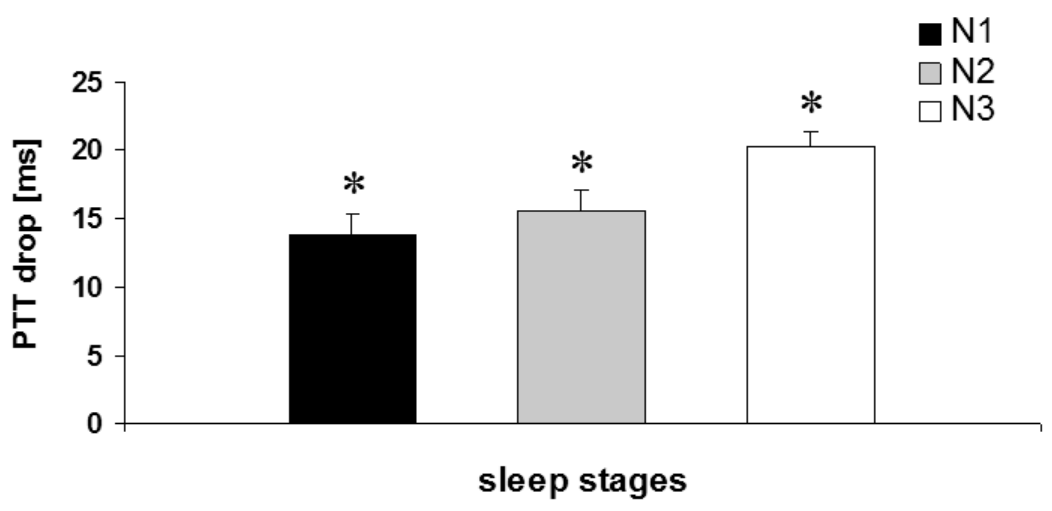

Figure 3. PTT shortening for sleep stages N1, N2 and N3 $(n=10)$.

We compared PTT shortening in correlation with AHI, ArI and DI. Pearson correlation analysis is shown in Table 1.
The Pearson correlation analysis demonstrated greater dependence of PTT shortening on ArI than AHI and DI. Correlation between 
PTT and ArI was very significant $(p=.0001)$. The correlations PTT/AHI $(p=.032)$ and PTT/ DI $(p=.017)$ were also great, but not with as much significance.

Dependence of PTT by ArI means that PTT can be used as a good indicator of sleep fragmentation (ArI is an indicator of disturbed sleep) before the deployment of the clinical picture of apneic pauses (AHI and DI). PTT is as good as EEG micro-arousals at predicting subjective sleepiness. So PTT detects subcortical/autonomic arousals.

Table 1. Pearson correlation analysis between PTT, AHI, ArI and DI $(n=10)$.

\begin{tabular}{|c|c|c|c|c|c|}
\hline & & PTT & AHI & ARI & DI \\
\hline \multirow{2}{*}{ PTT } & $\begin{array}{c}\text { Pearson } \\
\text { Correlation }\end{array}$ & 1 & $.675^{*}$ & $.922^{* *}$ & $.728^{*}$ \\
\hline & Sig. (2-tailed) & & 0.032 & 0 & 0.017 \\
\hline \multirow{2}{*}{ AHI } & $\begin{array}{l}\text { Pearson } \\
\text { Correlation }\end{array}$ & $.675^{*}$ & 1 & $.798^{* *}$ & $.781^{* *}$ \\
\hline & Sig. (2-tailed) & 0.032 & & 0.006 & 0.008 \\
\hline \multirow{2}{*}{ ARI } & $\begin{array}{l}\text { Pearson } \\
\text { Correlation }\end{array}$ & $.922^{* *}$ & $.798^{* *}$ & 1 & $.847^{* *}$ \\
\hline & Sig. (2-tailed) & 0 & 0.006 & & 0.002 \\
\hline \multirow{2}{*}{ DI } & $\begin{array}{l}\text { Pearson } \\
\text { Correlation }\end{array}$ & $.728^{*}$ & $.781^{* *}$ & $.847^{* *}$ & 1 \\
\hline & Sig. (2-tailed) & 0.017 & 0.008 & 0.002 & \\
\hline
\end{tabular}

*. Correlation is significant at the 0.05 level (2-tailed)

**. Correlation is significant at the 0.01 level (2-tailed)

\section{DISCUSSION}

Elite athletes are not spared the problem of sleep deprivation. In some sports, especially judo, heavy athletics, etc. the percentage of those suffering from sleep disorders is higher than that of those not engaged in sport (Rankov et al., 2010). As we already mentioned above, for athletes the loads performed after sleep deprivation showed a decrease in the fatigue onset time (Myles et al., 1985; Martin, 1981); and the period of sensitive perceptions is extended. Remes, et al. (1985) investigate plasma levels of certain androgens important for athletes after $21 \mathrm{~km}$ march with 11 well-trained and 11 poorly trained military newcomers after sleepdeprivation. They found that morning levels of testosterone, luteinizing hormone and androstenedione had significantly diminished after sleep-deprived stress. Souissi et al. (2007) monitored anaerobic reduction of force after
36 hours of sleep deprivation.

Plasma cortisol levels rise during periods of disturbed sleep and can lead to injuries and overtraining. High levels of cortisol explain the increased irritability and irascibility among sleep-deprived athletes.

Sleep deprivation worsens coordination and accuracy in sports like hurdles and sports games. Another effect is the reduction of reaction time. There is a general deterioration in the sport tactical opportunities and proper adversarial decision making.

Slow-wave sleep is critical for athletes because it covers part of the cycle in which Human growth hormone is secreted by the pituitary gland. Human growth hormone not only has an anabolic effect, but also stimulates fat burning and normalization of muscle biochemistry and therefore is considered as one of the key recovery hormones. 
Alternating exercise to sleep and rest is an important aspect of the recovery process and developing a greater sports opportunity. Chronic lack of sleep, especially in heavy training regime before competition, leads to serious negative consequences. An active sports person needs a longer sleep than the usual 6-9 hours per day particular of those not engaged in sport.

Among young athletes, sleep breathing disorders are characterized by discrete changes. The standard screening methods for these sleep disturbances detect airflow change (AHI) or saturation changes (DI). Based on correlation analysis, however, we found that changes in these parameters are at later stage of disease development and are unreliable for early observation of sleep deprivation.

\section{CONCLUSION}

PTT proves a reliable, easy to use, noninvasive and inexpensive method for early screening of sleep breathing disorders. Therefore, we strongly recommend its wide use in monitoring athletes' sleep.

In conclusion - prevention and advanced detection of discrete sleep deprivation with the use of relatively simple methods would undoubtedly help answer many questions related to poor recovery in sport. The adequate treatment of the problem of sleep deprivation would improve not only performance but also athletes' quality of life.

\section{REFERENCES}

Atlas Task Force of the American Sleep Disorders Association. (1992). Sleep., Vol. 15, No 2, pp. 173-184.

Caples, S.M., Garcia-Touchard, A., Somers, V.K. (2007). Sleep-disordered breathing and cardiovascular risk. Sleep., Vol. 30, No 3, pp. 291-303. Review.

Catcheside PG, Chiong SC, Mercer J, Saunders NA, McEvoy RD. (2002). Nonin- vasive Cardiovascular markers of acoustically induced arousal from non-rapid-eye-movement sleep. Sleep. No 25(7), pp. 797-804.

Halász, P., Kundra, O., Rajna, P., Pál, I., Vargha, M. (1979). Micro-arousals during nocturnal sleep. Acta Physiol Acad Sci Hung. Vol. 54, No 1, pp. 1-12.

Krieger J, Schröder C, Erhardt C. (2003). Cortical arousal, autonomic arousal. Evaluation techniques and clinical importance. Rev Neurol (Paris). No 159 (11 Suppl), pp. 6S107112. Review. French.

Lofaso, F., Goldenberg, F., d'Ortho, M.P., Coste, A., Harf A. (1998). Arterial blood pressure response to transient arousals from NREM sleep in nonapneic snorers with sleep fragmentation. Chest. Vol. 113, No 4, pp. 985-991.

Martin, B.J. (1981). Effect of sleep deprivation on tolerance of prolonged exercise Eur J Appl Physiol Occup Physiol. Vol. 47, No 4, pp. 345-354.

Myles, W.S., (1985). Med. Sleep deprivation, physical fatigue, and the perception of exercise intensity. Sci. Sports Exerc. Vol. 17, No. 4, pp. 580-584.

Narkiewicz, K., Pesek, C.A., Kato, M., Phillips, B.G., Davison, D.E., Somers, V.K. (1998). Baroreflex control of sympathetic nerve activity and heart rate in obstructive sleep apnea. Hypertension. Vol. 32, No 6, pp.1039-1043.

Naschitz JE, Bezobchuk S, MussafiaPriselac R, Sundick S, Dreyfuss D, Khorshidi I, Karidis A, Manor H, Nagar M, Peck ER, Peck S, Storch S, Rosner I, Gaitini L. (2004). Pulse transit time by-wave-gated infrared photoplethysmography: review of the literature and personal experience. J Clin Monit Comput. No 18 (5-6), pp. 333-342. Review.

Pitson, D., Chhina, N., Knijn, S., van Herwaaden, M., Stradling, J. (1994). Changes in pulse transit time and pulse rate as markers of arousal from sleep in normal subjects. Clin Sci 
(Lond). Vol. 87, No 2, pp. 269-273.

Pitson, D.J., Stradling, J.R., Pitson, D.J., Stradling, J.R. (1998). Autonomic markers of arousal during sleep in patients undergoing investigation for obstructive sleep apnoea, their relationship to EEG arousals, respiratory events and subjective sleepiness. J Sleep Res. Vol. 7, No 1, pp. 53-59.

Rankov, Kr., Nikolova, M., Stanchev, N., Mihajlov, V., Kirov, P.(2010). Sleepapnea prevalence among elite athletes, Sport\&Science, Extra issue.

Remes K., Kuoppasalmi, K., Adlercreutz, H. (1985). Effect of Physical Exercise and Sleep Deprivation on Plasma Androgen Levels: Modifying Effect of Physical Fitness. Int J Sports Med., Vol. 6, No 3, pp. 131-135.

Schieber, J.P., Muzet, A., Ferriere, P.J. (1971). Phases of spontaneous transitory activation during normal sleep in humans. Arch Sci Physiol (Paris). Vol. 25, No 4, pp. 443-465. French.

Smith, R.P., Argod, J., Pepin, J.L., Levy, P.A. (1999). Pulse transit time: an appraisal of potential clinical applications. Thorax. Vol. 54, pp. 452-457.

Somers, V.K., Dyken, M.E., Clary, M.P., Abboud, F.M. (1995). Sympathetic neural mechanisms in obstructive sleep apnea. J Clin Invest. Vol. 96, No 4, pp. 1897-1904.

Souissi, N., Bessot, N., Chamari, K., Gauthier, A., Sesboüé, B., Davenne, D. (2007). Effect of time of day on aerobic contribution to the 30-s Wingate test performance. Chronobiol Int. Vol. 24, No 4, pp. 739-748.

Souissi, N., Sesboüé, B., Gauthier, A., Larue, J., Davenne, D. (2003). Effects of one night's sleep deprivation on anaerobic performance the following day. Eur J Appl Physiol., Vol. 89, No 3-4, pp. 359-366.

Terzano, M.G., Mancia, D., Salati, M.R., Costani, G., Decembrino, A., Parrino, L. (1985). The cyclic alternating pattern as a physiologic component of normal NREM sleep. Sleep. Vol. 8, No. 2, pp. 137-145.

VanHelder, T., Radomski., M.W. (1989). Sleep deprivation and the effect on exercise performance. Sports Med, Vol. 4, pp. 235-247.

\section{Corresponding author:}

Krassimir Rankov

Department of Physiology and Biochemistry National Sports Academy "Vassil Levski" Studentski grad, 21, Acad. Stefan Mladenov str. Sofia 1700, Bulgaria E-mail: krankov@gmail.com 